\title{
A coastal trial facility for high voltage composite cross- arms
}

DOI:

10.1109/ELINSL.2012.6251430

Link to publication record in Manchester Research Explorer

\section{Citation for published version (APA):}

Zachariades, C., Cotton, I., Rowland, S. M., Peesapati, V., Green, P. R., Chambers, D., \& Queen, M. (2012). A coastal trial facility for high voltage composite cross-arms. In Conference Record of IEEE International Symposium on Electrical Insulation/Conf Rec IEEE Int Symp Electr Insul (pp. 78-82) https://doi.org/10.1109/ELINSL.2012.6251430

Published in:

Conference Record of IEEE International Symposium on Electrical Insulation|Conf Rec IEEE Int Symp Electr Insul

\section{Citing this paper}

Please note that where the full-text provided on Manchester Research Explorer is the Author Accepted Manuscript or Proof version this may differ from the final Published version. If citing, it is advised that you check and use the publisher's definitive version.

\section{General rights}

Copyright and moral rights for the publications made accessible in the Research Explorer are retained by the authors and/or other copyright owners and it is a condition of accessing publications that users recognise and abide by the legal requirements associated with these rights.

\section{Takedown policy}

If you believe that this document breaches copyright please refer to the University of Manchester's Takedown Procedures [http://man.ac.uk/04Y6Bo] or contact uml.scholarlycommunications@manchester.ac.uk providing relevant details, so we can investigate your claim.

\section{OPEN ACCESS}




\section{A Coastal Trial Facility for High Voltage Composite Cross-arms}

\author{
C. Zachariades, I. Cotton, S. M. \\ Rowland, V. Peesapati, \\ P.R. Green \\ School of Electrical and Electronic \\ Engineering \\ The University of Manchester \\ Manchester, M13 9PL, \\ United Kingdom \\ I.Cotton@manchester.ac.uk
}

\author{
D. Chambers \\ EPL Composite Solutions Ltd \\ Loughborough, LE11 1QJ, \\ United Kingdom
}

\author{
M. Queen \\ SSEPD plc \\ Perth, PH1 3AQ, United Kingdom
}

\begin{abstract}
A trial site has been developed within a substation on the North East coast of Scotland for electrical testing high voltage composite cross-arms. A $400 \mathrm{kV}$ transformer energizes two crossarms installed on a lattice tower oriented at $90^{\circ}$ from each other. A custom made protection system has been designed to keep the equipment within operating limits and minimize potential damage from faults. The purpose of the trial is to monitor the electrical performance of the cross-arms by measuring the leakage current on the surface of the insulating members. Weather monitoring equipment that includes a weather transmitter, a present weather detector and a solar sensor is used to correlate electrical behavior with specific weather phenomena. Cameras overlooking the cross-arms provide information regarding pollution accumulation and snow accretion. A data acquisition and control platform is responsible for recording the measurements. The monitoring system is capable of compiling and transmitting wirelessly a summary of the leakage current and weather information every five minutes.
\end{abstract}

Cross-arm; composite; insulator; transmission line, NCI, test facility, protection.

\section{INTRODUCTION}

The demand for electrical power driven by technological growth and the subsequent improvement in living standards is constantly growing. At the same time distributed generation and renewable resources are changing the power flows across the transmission network pushing some lines closer to their ampacity limit. The aforementioned factors coupled with rising land prices and difficulties in obtaining permissions for new overhead lines are forcing the power sector to seek economically viable solutions for improving the power transfer capabilities of existing infrastructure.

One of the most attractive solutions to this problem is the installation of composite cross-arms in the place of steel lattice cross-arms on the existing pylons which can be achieved with minimal modifications, contrary to alternatives. The benefits of this technology are not limited to the uprating of existing overhead lines. Since a separate insulator string is no longer required, the conductor can be physically raised reducing electromagnetic radiation at ground level. Furthermore, the right-of-way of lines using composite cross-arms can be minimised since the tower footprint can be reduced both in height and in width. The compaction of dimensions can also make the towers less obtrusive in the surrounding environment $[1]$.

A novel composite cross-arm for overhead lines of up to $400 \mathrm{kV}$ has been developed. The cross-arm consists of four insulating members, end fittings, field grading devices and a nose connection for the attachment of the conductor. The two main structural elements of the assembly have a unique noncylindrical geometry which makes them more resistant to bending and buckling than conventional insulators. As a result, they can also be made lighter and manufactured cheaper than conventional insulators with similar mechanical requirements.

Following the installation of four prototype cross-arms on a decommissioned line in the Scottish Highlands [2], a live trial is taking place in a coastal location of northern Scotland.

\section{PURPOSE OF THE TRIAL}

Contrary to the previous unenergised trial where the main purpose was to monitor the mechanical performance of the

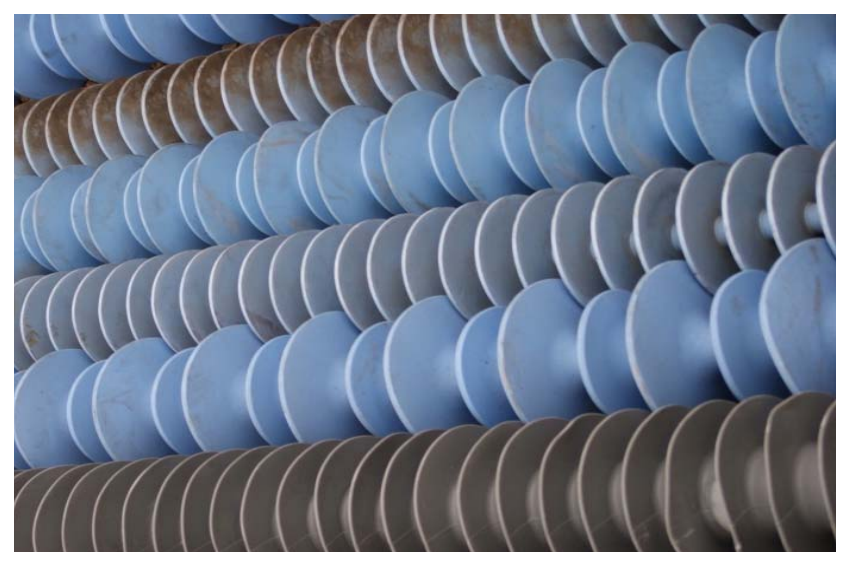

Figure 1. Insulators comprising the reference cross-arms 
cross-arms [2], this trial focuses on observing the electrical behaviour of the whole cross-arm and how this changes in relation to the variable environmental conditions.

Before the novel cross-arms are installed however, reference cross-arms will be deployed for a period of two months. These reference cross-arms comprise of various $400 \mathrm{kV}$ insulators some of which have been in service for several years. They also vary in length, shank diameter, shed diameter and profile (Fig. 1). The purpose of this initial trial is twofold. Firstly, to commission, test and calibrate the instruments in the actual environment where they will be operating. Secondly, to study how traditional insulators perform and obtain measurements for comparison.

\section{THE SITE}

A substation was identified on the east coast of Scotland able to accommodate a small lattice tower on which two composite cross-arms have been installed. The latitude of the location combined with its proximity to the sea provides the opportunity to examine electrical performance in an environment with high conductivity pollution and wide temperature variations. These conditions are amongst the most severe the cross-arms will face when they are put in service. The two cross-arms are designed to be installed at an orientation of $90^{\circ}$ from each other to investigate the effect of the direction of the prevailing weather.

To electrically stress the cross-arms equivalent to a $400 \mathrm{kV}$ phase-to-phase installation they are energised at $231 \mathrm{kV}$ phaseto-ground by a transformer that is powered from the $415 \mathrm{~V} \mathrm{3-}$ phase supply of the substation. The transformer is rated at 50 $\mathrm{kVA}$ continuous operation or up to $100 \mathrm{kVA}$ for 15 minutes per hour. The high voltage (HV) ends of the two cross-arms are

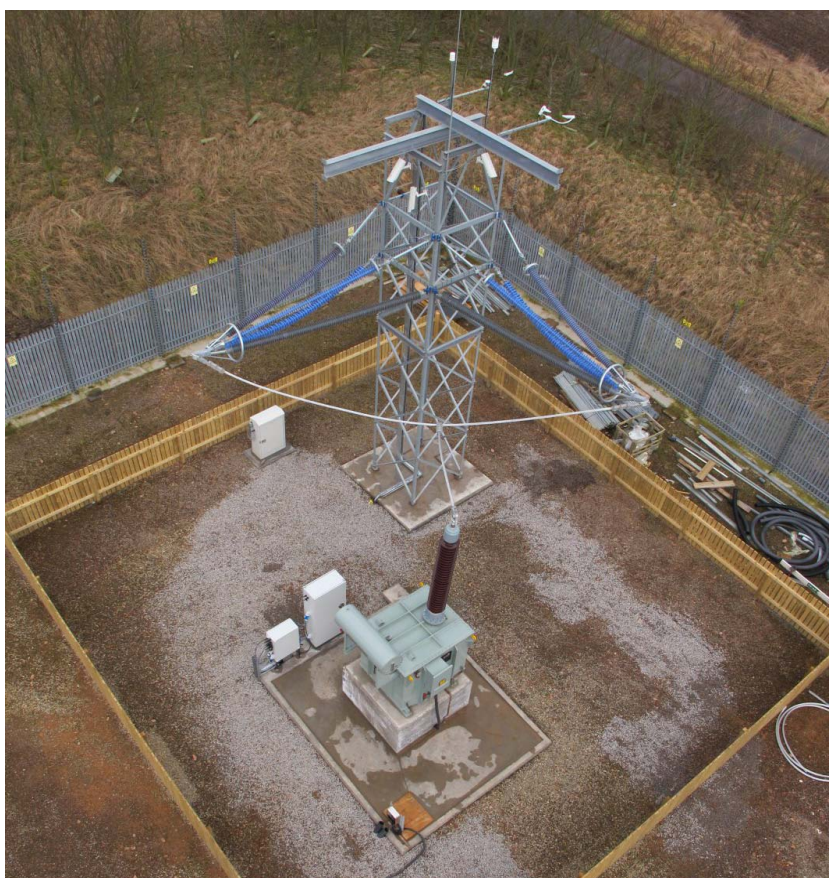

Figure 2. Trial site overview. The reference cross-arms consist of a range of insulator designs connected by an $8 \mathrm{~m}$ span of $400 \mathrm{kV}$ conductor which in turn is connected to the HV bushing of the transformer. An overview of the site is shown in Fig. 2.

\section{PROTECTION SYSTEM}

\section{A. Requirements}

The components of this trial constitute a small scale power system and, despite its relative simplicity, it requires electrical protection. A fast, reliable and sensitive protection system was designed specifically for the trial to keep the equipment within operating limits and prevent or at least minimise the damage from potential faults.

With the data provided by the substation administrator a fault analysis for different scenarios was performed that gives the following fault level values for a bolted fault:

- $415 \mathrm{~V}$ phase-to-phase: $3031 \mathrm{~A}$.

- $415 \mathrm{~V}$ phase-to-ground: $935 \mathrm{~A}$.

- $415 \mathrm{~V}$ phase-to-phase-to-ground: $3333 \mathrm{~A}$.

- $231 \mathrm{kV}$ phase-to-ground: $1351 \mathrm{~A}$

A diagram of the protection system is shown in Fig. 3.

\section{B. Overcurrent Protection}

To protect against winding faults in the transformer, a Definite Time Overcurrent relay is used on the low voltage (LV) input to the transformer. The steady state maximum load current is calculated to be $241 \mathrm{~A}(100 \mathrm{kVA}$ at $415 \mathrm{~V})$ but the relay is set using a slightly higher $(+20 \%)$ value of $288 \mathrm{~A}$ to provide a margin for short time transients. The $5 \mathrm{~A}$ relay is fed through a $400 / 5$ current transformer (CT) and is set at $72 \%$ (288/400) with a trip time setting of $0.25 \mathrm{~s}$ to prevent the higher inrush current tripping the system, an inhibit time of $1 \mathrm{~s}$ and a hysteresis of $5 \%$.

\section{Insrush Protection}

In order to protect the system from voltage dips as a result of high magnetising inrush currents, the transformer is energised through $0.5 \Omega$ resistors, limiting the inrush current to 830 A. The resistors are rated at $40 \mathrm{~kW}$ for five seconds and must be taken out of the circuit before they overheat, therefore the following energisation sequence is employed:

1. Close command given to control panel.

2. The primary contactor energises the transformer through resistors and the first timer starts.

3. After two seconds, the bypass contactor closes and the second timer starts.

4. After two seconds, the primary contactor opens and disconnects the resistors.

To prevent current from flowing continuously through the resistors in case of a contactor or timer failure, a 5 A overcurrent relay fed by a $400 / 5$ CT is used. The maximum continuous current through the resistors based on the thermal rating would be $92 \mathrm{~A}$ and using $80 \%$ of that the relay is set at 


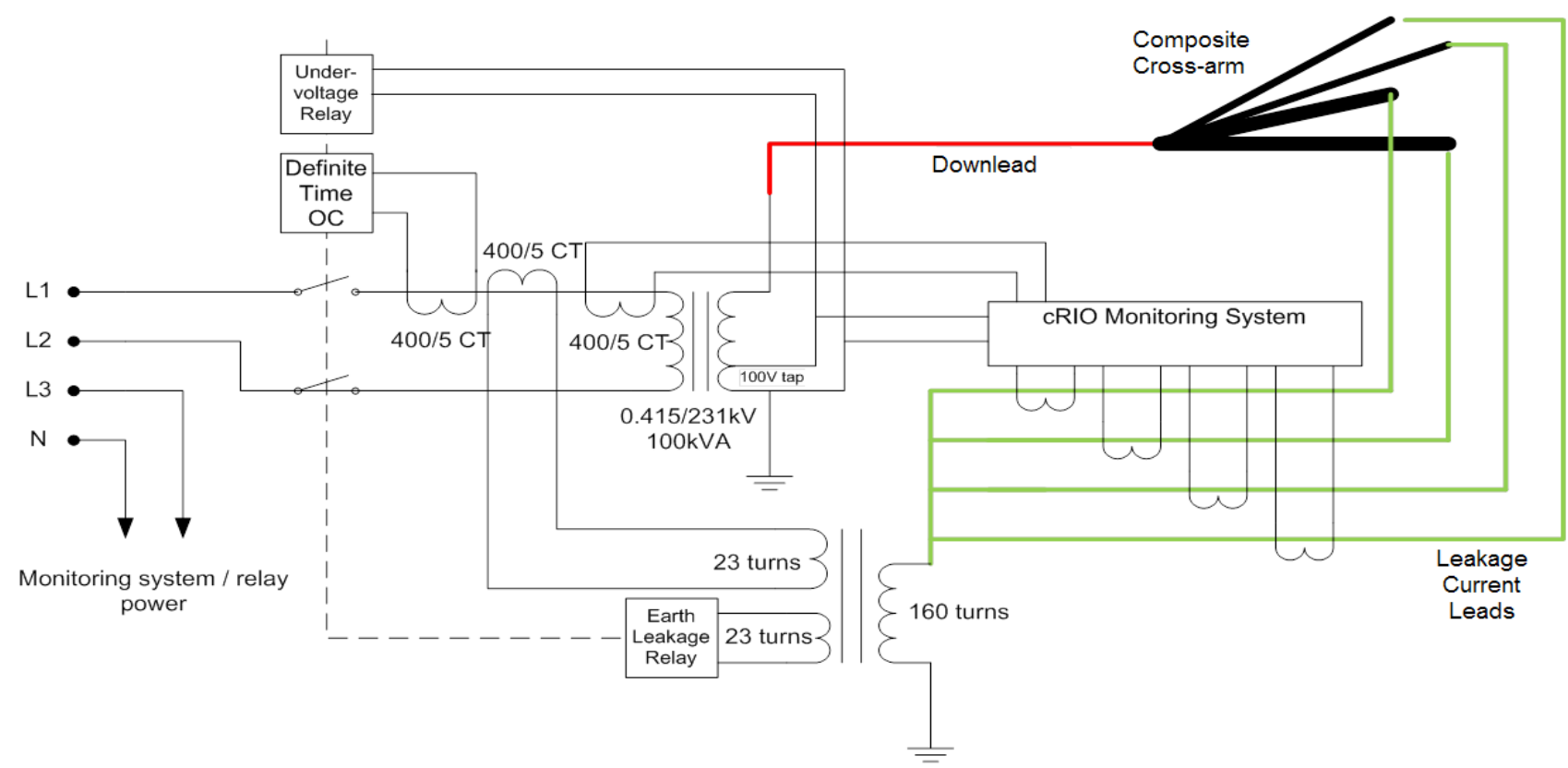

Figure 3. Protection system diagram

$19 \%(74 / 400)$ with a trip time setting of $5 \mathrm{~s}$, an inhibit time of 1 $\mathrm{s}$ and a hysteresis of $5 \%$.

\section{Undervoltage Protection}

A secondary undervoltage protection is installed to complement the overcurrent protection. The undervoltage relay is connected to a secondary $100 \mathrm{~V}$ tap of the transformer high voltage winding. To calculate the appropriate setting for the relay the following parameters were considered:

- Transformer impedance: 5\%.

- Transformer output voltage (secondary tap): $100 \mathrm{~V}$.

- Minimum statutory supply requirement: $-6 \%$ or 0.94 p.u.

- Margin: $95 \%$.

From the above, the trip level is calculated to be:

$$
\text { Trip Level }=100 \mathrm{~V} \times 0.94 \times 0.95 \times 0.95 \approx 85 \mathrm{~V}
$$

Therefore, the voltage seen by the relay would be:

$$
\text { Voltage at Relay }=(85 \mathrm{~V} \times 240 \mathrm{~V}) / 110 \mathrm{~V} \approx 185 \mathrm{~V}
$$

The relay is set at $62 \%(185 / 300)$ with a trip time of $1 \mathrm{~s}$.

\section{E. Differential Protection}

The final form of protection installed is a differential system which relies on a balanced current being seen in the low voltage winding of the transformer and at the low voltage end of the cross-arm members. Using a three winding transformer with the turns ratio set to account for the high voltage transformer turns ratio, any imbalance in the low and high voltage currents which would indicate a phase to earth fault will drive current through a third winding which supplies the overcurrent relay.

\section{MONITORING SYSTEM}

\section{A. Leakage current measurement}

As polymeric insulators age, their withstand capability reduces. The ageing process is often accelerated in polluted environments because the hydrophobicity of the material decreases more rapidly. Consequently, the continuous water paths formed on the surface of the insulator allow currents to flow that may result in more intense arcing activity [3]. Hence, leakage current is a good indication on how the electrical performance of the insulator changes over time [4].

To measure the leakage current from the composite crossarms, each of their members is installed on the tower using brackets which isolate them from earth. At the LV end of each member a shielded cable is attached that runs down the tower and into the monitoring enclosure. There, the individual cables are connected through $20 \Omega$ resistors to a commercial data acquisition (DAQ) and control platform, responsible for recording the leakage current signals in the form of voltage. The software running on the DAQ platform is programmed to detect changes in the signals and above a certain threshold accelerate the acquisition rate to capture high leakage current events with better resolution. 


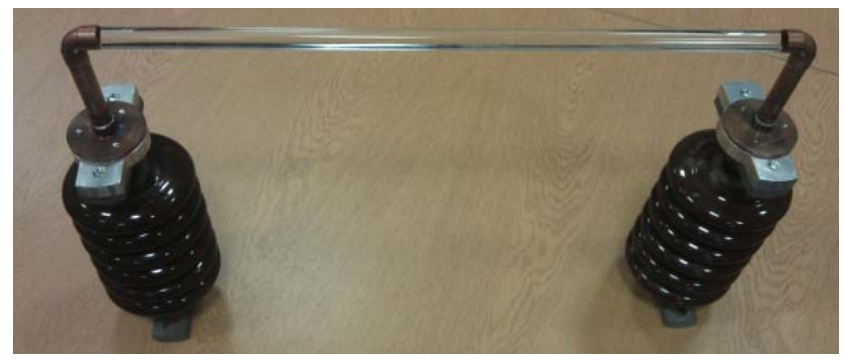

Figure 4. Glass rod conductivity measurement system

Additionally, a separate system for measuring the conductivity of a glass rod is installed on the tower at the same height as the cross-arms. The system consists of a $15 \mathrm{~mm}$ diameter glass rod, two copper pipes and two $11 \mathrm{kV}$ porcelain insulators to isolate the system from earth (Fig. 4). The rod is energised by a $50 \mathrm{~V}$ transformer through a $500 \Omega$ resistor and its leakage current cable terminates through a $50 \Omega$ resistor to another channel of the DAQ platform. Its purpose is to provide reference values for the conductivity of the pollution present at the site which will help identify the pollution severity level using an identical system in the laboratory.

\section{B. Weather monitoring}

In order to be able to correlate the manifestation of leakage current and/or flashover events to specific environmental conditions, three weather monitoring instruments are installed at the top of the lattice tower.

Firstly, a small, lightweight weather transmitter can measure wind speed and direction, precipitation, atmospheric pressure, temperature and relative humidity. The precipitation and wind sensors are heated to prevent snow accumulation and maintain the accuracy of measurements. It is powered by a 12 V DC supply located in the monitoring enclosure and outputs serial data to the DAQ platform using the RS485 communications protocol.

Secondly, a 'present weather' detector (PWD) combines the measurements of precipitation water content, optical scatter and temperature to evaluate the prevailing visibility and weather type. Specifically, it characterises the weather as one of the following types: no precipitation, precipitation, drizzle, rain, snow or sleet. The visibility estimation is provided in meters up to $2 \mathrm{~km}$ and is categorised into one of the following types: clear, mist, haze or smoke or dust. Similarly to the weather transmitter, the PWD is powered by a $12 \mathrm{~V}$ supply, but its heaters are powered by a more potent $24 \mathrm{~V}$ supply. Its data are transmitted using the RS485 communications protocol to the DAQ platform in $15 \mathrm{~s}$ intervals.

Thirdly, to measure solar irradiance, a pyranometer is installed. The intensity of solar radiation affects the speed at which moisture evaporates from the surface of insulators. Furthermore, UV radiation directly affects the ageing of composite materials and the sun impacts bio-film development. The pyranometer uses a thermopile detector to output a voltage signal in the range of $0-20 \mathrm{mV}$ and can measure a maximum irradiance of $2000 \mathrm{~W} / \mathrm{m}^{2}$.

\section{Cameras}

Four cameras are installed as part of the monitoring system. One of them is placed on the substation building over-looking the entire trial site and provides visual confirmation regarding the weather conditions in the immediate vicinity (Fig 2). The other three cameras are placed on the tower. Two of them monitor the cross-arms from above (Fig. 5) to capture snow and ice accretion patterns while the third is focused on one of the compression members to record water behaviour, pollution accumulation and possible changes in hydrophobicity (Fig. 6). The three tower cameras are powered by the $12 \mathrm{~V}$ supply in the monitoring enclosure while the site camera is powered directly from the mains supply of the substation.

\section{Data acquisition, storage and transmission}

A commercial DAQ and control platform is responsible for collecting the data from the various instruments. Leakage current readings are taken once every millisecond while weather data is recorded once every five seconds. Moreover, the DAQ platform collects data related to the transformer powering the trial, such as supply and output voltage. All the leakage current and weather data are initially stored locally inside the monitoring enclosure on a flash drive. The camera recordings are stored on SD cards installed inside the camera units themselves. The DAQ platform and the cameras are all connected to a wireless router within the monitoring enclosure via Ethernet cables. A PC located in the substation is

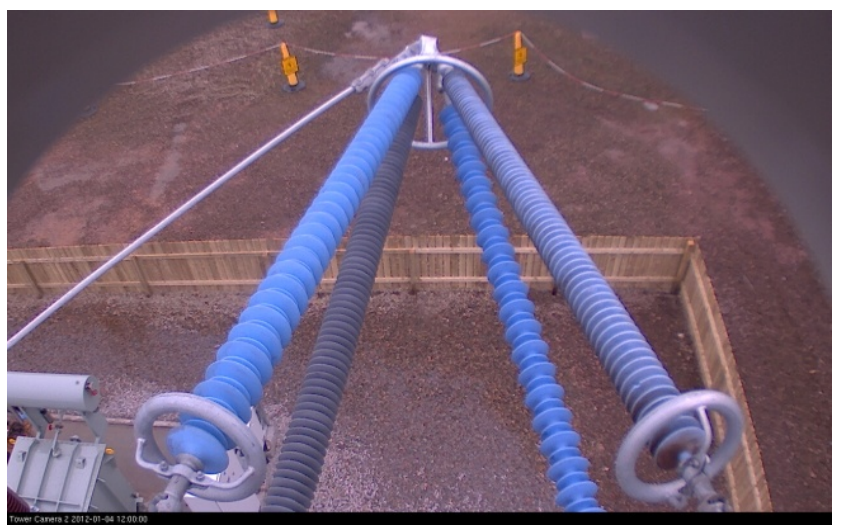

Figure 5. Cross-arm view (reference cross-arm)

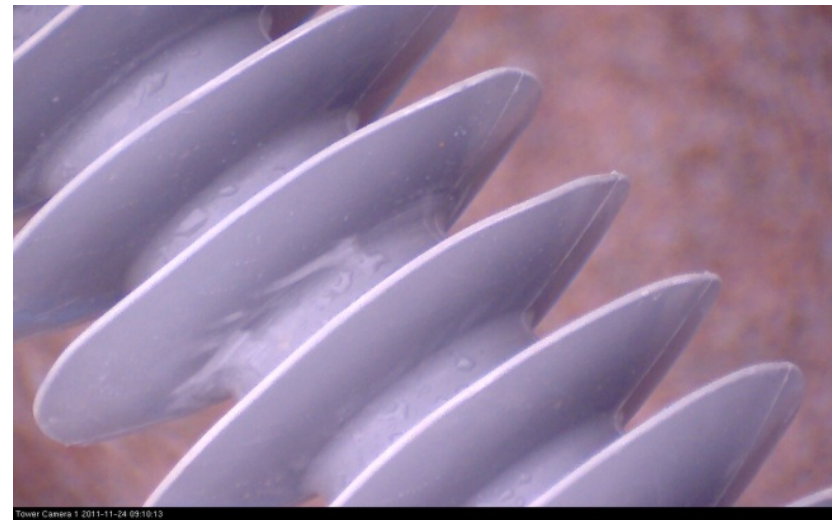

Figure 6. Compression member view (reference cross-arm) 


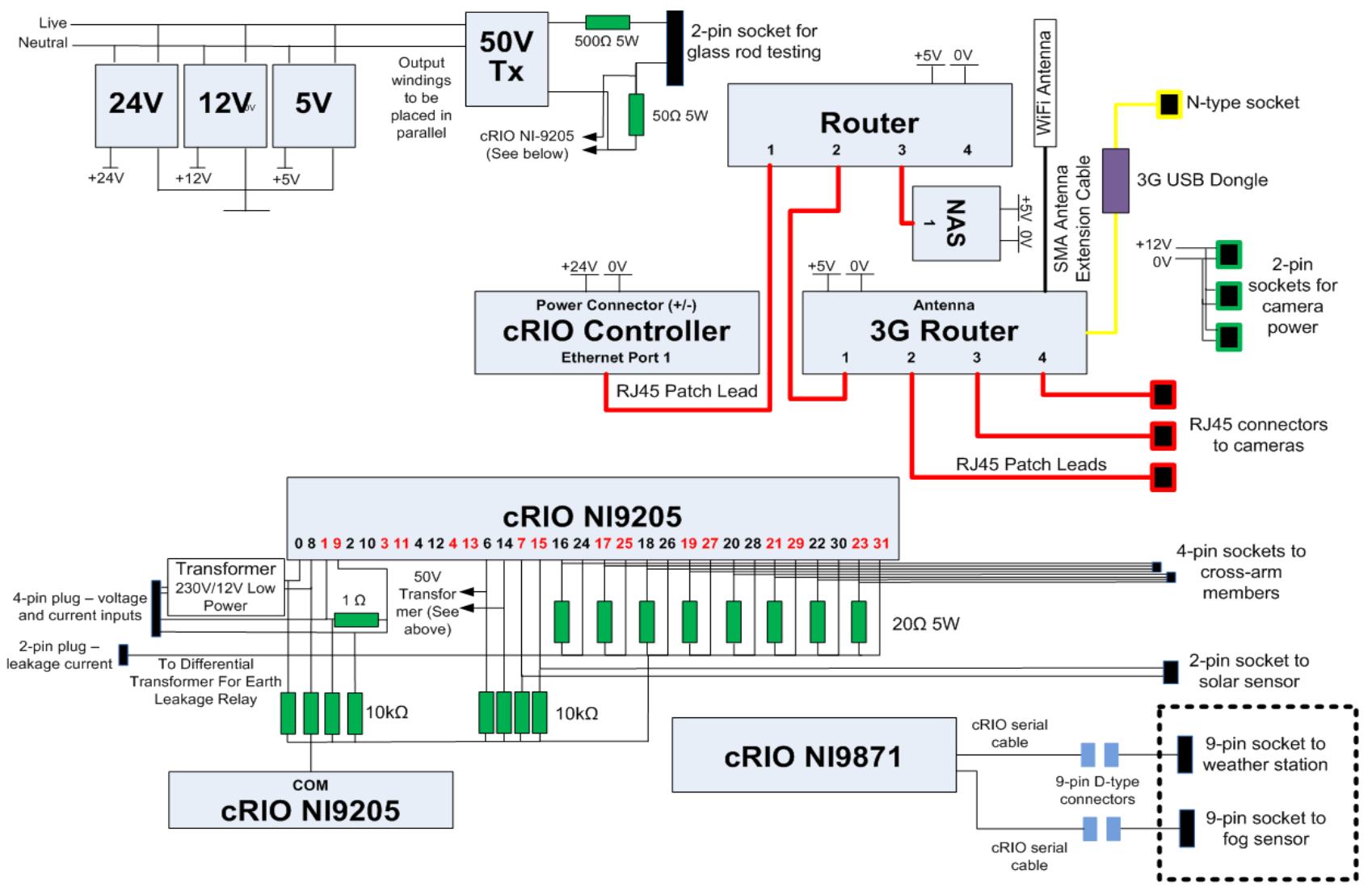

Figure 7. Monitoring system diagram

programmed to run an FTP script each day to pull all the data wirelessly and store them on a network attached storage (NAS) with mirrored drives.

A separate router in the monitoring enclosure connects to the $3 \mathrm{G}$ network via a USB dongle. The antenna lead of the dongle is extended to the top of the tower, using low loss coaxial cable where a $3 \mathrm{G}$ antenna has been installed to improve reception. Using the $3 \mathrm{G}$ link, data are transmitted periodically to a remote computer where, after processing, they are uploaded and displayed graphically as live weather and leakage current information on a website that updates every five minutes.

A diagram of the monitoring system is shown in Fig. 7.

\section{CONCLUSIONS}

A trial site on the North East coast of Scotland has been built for testing composite cross-arms. A lattice tower and a $400 \mathrm{kV}$ transformer have been installed within a substation. A bespoke protection system has been designed to interface the substation supply and the trial equipment. Furthermore, an instrumentation system has been developed whose primary purpose is to monitor leakage current on the surface of the cross-arm members. Using weather detection equipment and cameras, it will be possible to associate the electrical behaviour of the cross-arms to specific weather phenomena.
The results from this facility combined with electrical FEA [5] will lead to improvements in understanding the performance of such cross-arms. In this case, the installation of reference cross-arms before the novel composite cross-arms are put in place will give valuable calibration information.

\section{ACKNOWLEDGMENT}

The authors are grateful to SSEPD and National Grid for their support and permission to publish.

\section{REFERENCES}

[1] K. Kopsidas, S. M. Rowland, M. N. R. Baharom, I. Cotton, "Power transfer capacity improvements of existing overhead line systems," International Symposium on Electrical Insulation (ISEI), 2010.

[2] C. Zachariades, S.M. Rowland, I. Cotton, P.R. Green, C.A. Veerappan and D.Chambers, "A Trial Installation of High Voltage Composite Cross-arms," XVII International Symposium on High Voltage Engineering (ISH), August 2011.

[3] S.M. Rowland, Y. Xiong, J Robertson and S. Hoffmann, "Aging of silicone rubber composite insulators on $400 \mathrm{kV}$ transmission lines," IEEE Transactions on Dielectrics and Electrical Insulation, vol. 14, pp. 130-136, 2007.

[4] S.M. Rowland, K. Kopsidas and X. Zhang, "Ageing of Polyethylene ADSS Sheath by Low Currents," IEEE Transactions on Power Delivery, vol. 25, issue 2, pp. 947-952, 2010 .

[5] V. Peesapati, C. Zachariades, Q. Li, S.M. Rowland, I. Cotton, F. Allison, P.R. Green and D.Chambers, "3D Electric Field Computation of Composite Cross-arm," International Symposium on Electrical Insulation (ISEI), 2012, in press. 